\title{
Nonprofit Practitioners Chat Back: An Exploratory Content Analysis of Participant Responses to the National Council of Nonprofit's Webinar on the 2017 Tax Cuts and Jobs Act
}

\author{
${ }^{1}$ Anisfield School of Business, Ramapo College, Mahwah, N], USA, E-mail: rabzug@ramapo.edu
}

\begin{abstract}
:
As the first major overhaul of the United States' tax code in a generation, the passage of the Tax Cuts and Jobs Act of 2017 has particular significance for the operation of US nonprofit organizations. Provisions of the Tax Act, including raising the ceiling on individual standard deductions, imposing excise taxes on highly compensated nonprofit employees, repealing the individual mandate of the Affordable Care Act, etc., are causing great uncertainty and consternation within organizations of, and bridging, the nonprofit sector. In response to some of the initial confusion, the National Council of Nonprofits offered a webinar, entitled, "Now What: How the New Federal Tax Law Impacts Charitable Nonprofits" on January 11, 2018. A one-hour slide-show with voice-overs was complemented by a running "chat" of nonprofit listeners/participants. This exploratory study undertakes a content analysis of the one-hour nonprofit participant chat that accompanied the webinar in order to take a pulse of the concerns of the practitioners as the potential impact of the law was explicated.
\end{abstract}

Keywords: Tax Cuts and Jobs Act, practitioners, Neo-institutionalism

DOI: $10.1515 / \mathrm{npf}-2019-0010$

\section{Introduction}

On December 22nd of 2017, the Tax Cuts and Jobs Act became law in the United States of America. Opposed by large swaths of the nonprofit sector, the tax law garnered a "careful review from the nonprofit perspective" by David Thompson in the pages of the Nonprofit Quarterly that determined that the tax-law changes ranged from "bad to awful." (Thompson 2017). Burgeoning consensus on the detrimental impact of the Tax Cuts and Jobs Act prompted a last ditch, though ultimately unsuccessful effort, by Presidents and CEOs of the Council on Foundations, the National Council of Nonprofits and Independent Sector to issue a Joint Letter of Opposition to the Senate Tax Reform in December of 2017. The hurried passage of the bill by Christmas of 2017, meant that by the beginning of 2018, nonprofit leaders, practitioners, and advocates, were scrambling to try to understand the new provisions by which they would have to abide.

Since provisions of the Tax Act included raising the ceiling on individual standard deductions, imposing excise taxes on highly compensated nonprofit employees, and repealing the individual mandate of the Affordable Care Act, nonprofit organizations faced/are facing great uncertainty. In response to some of the initial confusion, the National Council of Nonprofits offered a webinar, entitled, "Now What: How the New Federal Tax Law Impacts Charitable Nonprofits" on January 11, 2018. A one-hour slide-show with voice-overs was complemented by a running "chat" of nonprofit listeners/participants. This exploratory study undertakes a content analysis of the one-hour nonprofit participant chat that accompanied the webinar in order to take a pulse of the concerns of the practitioners as the potential impact of the law was explicated.

Specifically, we ask, what were the top of mind issues expressed by nonprofit practitioners during a nationwide webinar addressing the potential impact of the Tax Cuts and Jobs Act of 2017? What tax law changes were most chatted about and what role, if any, did gender play in the frequency of specific chat topics mentioned and in chat room language conventions?

To explore answers to these questions, we first review the literature on organizational sense-making through a neo-institutional lens. We note specifically that the coercive process of changing the law to impact (nonprofit) organizations may be followed by a period of normative and mimetic institutionalizing practices whereby sense 
is made and equilibrium restored, and that these processes may be sped up with access to new(er) technologies such as the internet. We then review the literature on sense-making in internet chatting and introduce a gender lens into our model. After discussing our methodology, we present and discuss our preliminary findings leading to our tentative conclusion and its potential policy and organizational implications.

\section{Literature Review}

Neo-institutional theory reminds us that (nonprofit) organizations are (at least partially) structured, and sense is made, through processes of institutional isomorphism, including the coercive power of the state (DiMaggio and Powell 1983, 1991; Scott 2001), through changes in the legal environment (Edelman 1990, 1992). When the state changes direction-as with the Tax Cuts and Jobs Act of 2017, we would expect (nonprofit) organization practitioners to look to re-establish equilibrium and legitimacy (Suchman 1995). Sense-making and legitimacy in reaction to coercive pressures may be mediated through both mimetic and normative institutional processes.Edelman and Suchman (1997: 480) have noted that law "develops meaning through its application by organized professions, and it develops substance through its application by organizational compliance officers," the former a normative process and the latter a potentially mimetic process.

Today, as opposed to when neo-institutional theory was in its infancy, mimetic and normative processes may be more easily facilitated by technology (such as the internet) which can bring together practitioners and professionals from like organizations almost instantaneously and at scale. The advent of a chat room as a meeting place to bring together heretofore isolated and atomized individuals (Panyametheekul and Herring 2003) represents the creation of an alternative and immediate space for sense making. A webinar, sponsored by the bridging organization, the National Council of Nonprofits, can then be considered a venue where mimetic and normative processes can affect practitioner sense-making, and perhaps, eventual nonprofit structure and function. What organizational actors express and question during times of structural change may be a signal as to where resources and energy may flow. Practitioners chatting may provide insights into unmet information needs (White 2000; White, Abels, and Agresta 2004), and so may be particularly helpful to sector capacity builders.

It is also possible that practitioner pre-occupation, and even participation (Panyametheekul and Herring 2003; Soukup 1999; Khechine, Lakhal, Pascot, and Bytha, 2014) might have a gender component and so we account for that. Researchers have suggested that females, specifically in chat rooms, may participate more actively (Panyametheekul and Herring 2003), so we were interested to see if the pattern held for our nonprofit practitioners.

While some authors have suggested that the relative anonymity and/or new identity creation aspects of the internet have blurred traditional gendered patterns of communicating (Bing and Bergvall 1996; Rodino 1997), others have posited the lingering impact of gender in structuring online interaction. To that end, we were interested to explore potential differences in linguistic style between male and female chatters (Tannen 1994). As gender communications guru Deborah Tannen has suggested that in learning situations men ask fewer questions (Tannen 1994, 1995), we were curious to see if that held true in the webinar/chat room environment.

Further, past research has noted that male communicative goals which are more competitive (as opposed to women's more collaborative goals) may lead to increased topic shifting (Hill 2008; Prabhakaran, Arora, and Rambow 2014), so we were interested to see whether women chatters were more likely to stay on the webinar topic at hand.

Based on the preceding literature review, we were interested in exploring the following:

Research Question 1: What issues/concerns dominated the chat box of nonprofit practitioners during the National Council of Nonprofits webinar, "Now What: How the New Federal Tax Law Impacts Charitable Nonprofits" on January 11, 2018?

Research Question 2: To what extent did practitioner chat reflect the content of the webinar?

Research Question 3: What, if any, role did gender of chatting practitioner play in relative concern with top issues?

Research Question 4: What, if any, role did gender of chatting practitioner play in form of chat participation?

\section{Data and Methodology}

Using the text of the nation-wide chat that accompanied the January 11, 2018 National Council of Nonprofit's webinar, "Now What: How the New Federal Tax Law Impacts Charitable Nonprofits," a content analysis was conducted, with a particular emphasis on both categorizing issues of utmost importance to participants as 
well as exploring the role of gender in emphasis of topics and language usage. The author of this paper was a participant observer of the webinar and watched the discourse unfold in real time. By the end of the hour-long webinar, 264 chat contributions were recorded (for several thousand registrants) and coded for gender of writer (where discernible, based solely on naming conventions), theme, key words used, grammatical structure, and relevance to webinar topic. Word and theme counts (and clouds) were generated to determine the items of greatest participant preoccupation and chi-square analyses of association were employed to determine gender associations with theme and word frequencies as well as linguistic conventions.

\section{Preliminary Results}

Given the webinar's broad coverage of topics including: issues for nonprofits as employers (new withholding tax tables, rising health insurance premiums, elimination of many personal deductions for work-related items, and new excise taxes on highly compensated individuals), as fundraisers (consequences of raising the standard deduction to decrease the proportion of filers who itemize deductions), as policy watchers (states laws are likely to be changed in accommodation of new federal realities), and as service providers (girding for need to increase services at a time of falling revenue), we would expect a concomitant breadth in topic areas for the chat. chi-square tests of Association demonstrated significant independence between the content of the webinar, itself, and the content of the simultaneous participant chat. Specifically, the chat participants were relatively preoccupied with the issues of tax law curbs on high compensation in the sector, and, to a much lesser degree, definitions and examples of Unrelated Business Income Taxes (UBITS) and reimbursement for employee transportation as seen in counts of word frequencies illustrated in Table 1 and the word cloud derived from theme counts depicted in Figure 1.

Table 1: Word Frequency Counter (words mentioned more than 5 times).

\begin{tabular}{|c|c|}
\hline 102 & compensation \\
\hline 31 & webinar \\
\hline 14 & government \\
\hline 13 & access \\
\hline 12 & function \\
\hline 11 & donors \\
\hline 10 & unrelated \\
\hline 10 & transportation \\
\hline 10 & business \\
\hline 9 & pallotta \\
\hline 8 & lobbying \\
\hline 7 & thanks \\
\hline 7 & office \\
\hline 7 & home \\
\hline 7 & expense \\
\hline 7 & deduction \\
\hline 6 & $\operatorname{tax}$ \\
\hline 6 & pilot \\
\hline 6 & IRS \\
\hline 6 & critique \\
\hline
\end{tabular}


agree (5) audio (8) benefits (5) board (5) budget ${ }_{(12)}$

cap (9) care (11) changes (9) commuting (5)

compensation (8) corporate (6) david (6)

deduction (13) donate ()) $_{\text {donors (17) }}$

employees (13) funds (5)

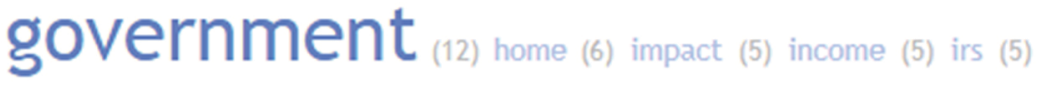

itemize (9) list (7) lobbying (7) lyne (5) making (5)

non-profit ${ }_{(15)}$ nonprofit $_{(12)} \mathrm{np}($ (11)

office (17) pay (11) people (12) private (5)

provide (10) public (10) report (6)

salary (35) $_{\text {service (10) sides (5) state (5) }}$

$\operatorname{tax}_{(15)}$ thank $_{(10)}$ think ${ }_{(14)}$ top (5) travel (5) buit (6) work

Figure 1: Word Cloud of Frequently Chatted Themes.

The first instance of "extended" chat room reflexive interactivity (chatters chatting with each other rather than to the presentation) came when the presentation turned to the Tax Act's provision that certain qualified transportation fringe benefits must be reported as unrelated business income. Starting with the question, "Does transportation include business travel?" twelve chats from eleven different chatters immediately followed. That thread was interrupted the minute after the presentation covered the tax on excess tax-exempt organization executive compensation, mentioning \$1 million dollar executive compensation. The thread started with " $\$ 1 \mathrm{M}$ compensation? I am working a [sic] the wrong nonprofit." Fourteen chats followed quickly until a chatter asked, "Will there be access to the PPT after this webinar??"

The next substantive issue that elicited reflexive interactivity was when a chatter asked, "Can you please list a few unrelated business activities, samples?" Twenty-one responses to that query were interspersed with folks complaining about an echo on the phone. After a few webinar logistics chats (i. e. "Can we get the slides from today's presentation," "I would also like the slides" etc.), the chatbar returned to the compensation topic with the chat, "Nobody should be making \$1 million and YES non-profits should have salary caps." At least 90 more chats engaged in a debate around whether any nonprofit should be paying over $\$ 1$ million in compensation. The word PILOT from the presentation caught a chatter's attention and the chatbar was briefly hijacked by a conversation kicked off by the chat, "What did PILOTs mean again?" Soon after, the compensation thread continued with the chat query, "is salary plus benefits perks etc. or straight salary?" At least thirteen other salary cap chats followed with a few nods to Dan Pallotta. Lobbying and 501 declarations represented the last new substantive thread but lasted only about 12 chats before the presentation summed up.

Per our first research question, the content analysis of the chat room suggested that the five substantive topics that most engaged the chatters were, in order of preoccupation of chatters: (1) executive compensation and salary caps in nonprofits, (2) what types of transportation benefits would now be taxed, (3) what are examples of UBITs, (4) what are PILOTS, and (5) nonprofit lobbying. Per the second research question, we note that while all five of the chatted about topics were mentioned during the hour-long presentation, no one of these merited more than one slide of the total 45 slides. All five topics, then, accounted for only $1 / 9$ of the total slide presentation. Per research question 2, we can suggest that the chatters stayed with their own topics of interest far more than they stayed with the presentation. With the chatters veering off subject, we turned to an exploration 
of the last two research questions on chat logistics and netiquette. Based on theories of chat room interaction, we explored gender as a variable in these communications.

We first noted that, for comments whose author's gender could be discerned (somewhat imperfectly due to the fluidity of gender naming norms), there was a slight female skew to the overall chatting as $60 \%$ of chat contributions were proffered by women. From a participant observer's perspective, it was impossible to determine the gender composition of the total webinar audience. Despite the female skew of commenting, gender was not related to the topics raised, their frequency, or their relevance to the webinar content. From a linguistic style perspective, gender was also not related to the asking of questions, nor the proffering of responses. The (non)findings on gender are summarized in Table 2 and Table 3.

Table 2: Summary of Relationships Between Gender of Chat Participant and Frequent Word/Themes.

\begin{tabular}{llll}
\hline $\begin{array}{l}\text { Gender and Frequent } \\
\text { Word/Theme }\end{array}$ & $\mathbf{X}^{\mathbf{2}}$ & $\mathbf{p}$-value & Result \\
\hline "Compensation" & 1.33 & 0.2489 & Not Significant \\
"Government" & 1.55 & 0.2129 & Not Significant \\
"Webinar" & 0.36 & 0.5460 & Not Significant \\
"Donors" & 0.09 & 0.7541 & Not Significant \\
"UBIT" & 0.49 & 0.4854 & Not Significant \\
"Transportation" & 0.15 & 0.7010 & Not Significant \\
\hline
\end{tabular}

Table 3: Relationships Between Gender of Chat Participant and Web Linguistics.

\begin{tabular}{llll}
\hline Gender and Web Linguistics & $\mathbf{X}^{\mathbf{2}}$ & p-value & Result \\
\hline Theme Related? & 0.132 & 0.7158 & Not Significant \\
Response to Query? & 1.81 & 0.1779 & Not Significant \\
Question? & 1.13 & 0.2868 & Not Significant \\
\hline
\end{tabular}

Such non-findings on gender support Bing and Bergvall's, (1996) and Rodino's (1997) concerns about whether asking questions about gender differences online serves mostly to re-inforce binary gender differences as the evidence for exploring such dualisms online is weak, at best. This study, then reinforces the arguments that gender constructions online do not so easily fit into dualist categories (Rodino 1997).

From a nonprofit content, perspective, however, gender differences were telling. Analyzing the preferred topic of chat (compensation) based on gender, we were able to surmise that the women chatters were significantly more likely than men to take a dim view of high compensation for managers in the sector.

It was a woman chatter who returned the chatbar to the topic of compensation with the comment "Nobody should be making \$1 mission and YES non-profits should have salary caps."

It was a male chatter who reminded the chatbar, "this is a capitalist economy. That organization thinks that employee is providing value at whatever the salary level is." Although some of the male chatters also found million dollar nonprofit salaries to be scandalous while some women chatters supported nonprofit salaries comparable to for-profit counterparts, the overall gender pattern (as demonstrated in Table 4) of the chats was for women to be more outraged at the high salaries that the men supported. A chi-square test of association was significant at $\mathrm{p}<0.10$, suggesting a weak but provocative relationship between gender (female) and outrage at excessive compensation in the sector.

Table 4: Relationship Between Gender of Chat Participant and Support for High Compensation of Nonprofit Executives.

\begin{tabular}{llll}
\hline & Supportive & NOT Supportive & $\begin{array}{l}\text { Marginal Row } \\
\text { Totals }\end{array}$ \\
\hline Female & $14(16.67)$ & $11(8.33)$ & 25 \\
Male & $16(13.33)$ & $4(6.67)$ & 20 \\
Marginal Column Totals & 30 & 15 & 45
\end{tabular}

The chi-square statistic is 2.88 . The $\mathrm{p}$-value is 0.0897 . This result is significant at $\mathrm{p}<0.10$. 


\section{Tentative Conclusion}

Months (and years) after the passage of the Tax Cuts and Jobs Act of 2017, different fears, concerns, and realities have and will have emerged for nonprofit practitioners. This small study provides a snapshot of a certain nonprofit practitioner mindset that emerged directly after the contentious battle to pass the law. In real time, we were able to participant observe the juncture where a coercive institutional force (passing a new federal law) was met with an active sense-making process (a webinar of relevant constituencies) involving both normative and mimetic processes. From a neo-institutional theory perspective, then, this work helps us to understand how sense is made by actors/organizations subject to coercive institutional pressures. It also demonstrates how normative and isomorphic pressures can be created (through chats) in real time through technology that obviates geographic boundaries and limits. Specifically we observed that while normative forces (representatives from nonprofit infrastructure organization) tried to frame potential fallout from the new law, the constituent audience (perhaps under the influence of mimetic forces) had its own preoccupations and, ultimately agenda, for the "meeting."

From a nonprofit policy perspective, then, the work highlights a potential disconnect between what sectoral infrastructure actors deem important and what a self-selected audience takes away instead. The slide-show presented by the "experts" was wide-ranging and expansive, while the corresponding chat was fixated on just a select few intra-sectoral hot-button topics. Further study may determine whether the disconnect between expert sense-making and audience reaction was a somewhat lagged shocked reaction to a new reality or the lack of other avenues for practitioners to express concerns about intra-sectoral contentious issues. Research opportunities to explore such possibilities abound.

Finally, while the study suggests that gender may be increasingly beside the point in analyses of technological communication-it was not a significant element in the form of the discourse studies here-it likely remains predictive of attitudes within the nonprofit sector about the nonprofit sector. That too, is another avenue of potential fruitful future research.

\section{References}

Bing, J.M., and V.L. Bergvall. 1996. “The Question of Questions: Beyond Binary Thinking.” In Rethinking Language and Cender Research: Theory and Practice, edited by V.L. Bergvall, J.M. Bing, and A.F. Freed, 1-30. New York: Longman.

DiMaggio, P., and W. W. Powell. 1983. “The Iron Cage Revisited: Collective Rationality and Institutional Isomorphism in Organizational Fields." American Sociological Review 48 (2): 147-60.

DiMaggio, P..., and W.W. Powell. 1991. The New Institutionalism in Organizational Analysis. Chicago: University of Chicago Press.

Edelman, L. B. 1990. "Legal Environments and Organizational Covernance: The Expansion of Due Process in the American Workplace." American Journal of Sociology 95 (6): 1401-40.

Edelman, L. B. 1992. "Legal Ambiguity and Symbolic Structures: Organizational Mediation of Civil Rights Law." American Journal of Sociology 97 (6): $1531-76$.

Edelman, L. B., and M. C. Suchman. 1997. “The Legal Environments of Organizations.” Annual Review of Sociology 23 (1): 479-515.

Hill, M. L. G. 2008. “Staying on Topic, Changing the Topic: Language and Cender in the 1995 Louisiana Covernor's Race." The Social Science Journal 45 (2): 296-311.

Khechine, H., S. Lakhal, D. Pascot, and A. Bytha. 2014. “UTAUT Model for Blended Learning: The Role of Cender and Age in the Intention to Use Webinars." Interdisciplinary Journal of E-Learning and Learning Objects 10 (1): 33-52.

Panyametheekul, S., and S. C. Herring. 2003. "Cender and Turn Allocation in a Thai Chat Room." Journal of Computer-Mediated Communication 9 (1): JCMC913.

Prabhakaran, V, A Arora, and O. Rambow. 2014. “Staying on Topic: An Indicator of Power in Political Debates." Proceedings of the 2014 Conference on Empirical Methods in Natural Language Processing. Doha, Qatar, October: Association for Computational Linguistics.

Rodino, M. 1997. “Breaking Out of Binaries: Reconceptualizing Cender and Its Relationship to Language in Computer-Mediated Communication." Journal of Computer-Mediated Communication 3 (3): JCMC333.

Scott, W.R. 2001. Institutions and Organizations, 2nd ed. Thousand Oaks, CA: Sage.

Soukup, C. 1999. "The Gendered Interactional Patterns of Computer-Mediated Chatrooms: A Critical Ethnographic Study." The Information Society 15 (3): 169-76.

Suchman, M. C. 1995. “Managing Legitimacy: Strategic and Institutional Approaches." Academy of Management Review 20 (3): 571-610.

Tannen, D. 1994. Talking from 9 to 5: How Women's and Men's Conversational Styles Affect Who Cets Heard, Who Cets Credit, and What Cets Done at Work, 10019. William Morrow and Company, Inc., 1350 Avenue of the Americas: New York, NY.

Tannen, D. 1995. “The Power of Talk: Who Gets Heard and Why." Harvard Business Review 73 (5): 138-48.

Thompson, D. L. 2017. “The Good (?), the Bad, and the God-Awful: Nonprofit Bottom Lines on the House Tax Bill." Nonprofit Quarterly. Retrieved from November 6. https://nonprofitquarterly.org/2017/11/06/good-bad-god-awful-nonprofit-bottom-lines-house-tax-bill/.

White, M. D. 2000. "Questioning Behavior on a Consumer Health Electronic List." Library Quarterly 70 (3): 302-34.

White, M. D., E.C. Abels, and J. Agresta. 2004. "The Relationship between Interaction Characteristics and Answer Quality in Chat Reference Service." Online proceedings of the Virtual Reference Desk Conference. Cincinnati, OH, November 8-9, 2004. 